\title{
The Outcome of the Development of Multimedia and Activities to Enhance Knowledge about Arts and Cultures for Community Youths Through Social Lab
}

\author{
Kuntida Thamwipat ${ }^{1}$ \\ ${ }^{1}$ Faculty of Industrial Education and Technology, King Mongkut's University of Technology Thonburi, Bangkok, \\ Thailand \\ Correspondence: Kuntida Thamwipat, Faculty of Industrial Education and Technology, King Mongkut's \\ University of Technology Thonburi, Bangkok, Thailand
}

Received: February 9, 2019

Accepted: May 2, 2019

Online Published: June 29, 2019

doi:10.5539/ies.v12n7p10

URL: https://doi.org/10.5539/ies.v12n7p10

\begin{abstract}
This research was aimed to develop multimedia and activities to enhance knowledge about arts and cultures for community youths through social lab at the community under the bridge zone 1 , to determine the quality of the multimedia and activities, to examine the learning achievement of the community youths, to evaluate the satisfaction of the sampling group and to evaluate the after-action review (AAR) of the organizers. The research tools in this study included the quality evaluation form for contents, the quality evaluation form for media and activities, the learning achievement test, the satisfaction survey for the sampling group towards the multimedia and activities, and the activity to get after-action review (AAR) of the organizers. The sampling group consisted of people who had lived in the community under the bridge zone 1 for over 2 years had participated in this research from the beginning till the end. There were 120 people who filled out the questionnaires. They were chosen using purposive sampling method. The group included local people and community youths. The research results showed that the organizers ran the project about dancing performance alongside single-head drums for the community youths through social lab. The multimedia included vinyl media and video clips to teach dancing performance alongside music from single-head drums. The clips and teaching were made by students who got scholarship from KMUTT for their art and cultural skills and the fence-painting activity was done by graduate students from the LTM652 Principle and Theories of Mass Communication course. The organizers analyzed, designed and developed multimedia and activities in accordance with the ADDIE Model in the first semester of the academic year 2018. The quality of the contents was at a good level $(\overline{\mathrm{x}}=4.46, \mathrm{~S} . \mathrm{D}=0.26)$. The quality of the media and activities was at a very good level $(\overline{\mathrm{x}}=4.60, \mathrm{~S} . \mathrm{D}=0.26)$. The learning achievement of the students from their pre-test and post-test scores showed that their average post-test score was higher with statistical significance at the. 05 level. The satisfaction of the sampling group was at the highest level $(\overline{\mathrm{x}}=4.63$, S.D $=0.56)$, confirming the research hypothesis. The after-action review showed that it was at a good level. The organizers expressed their opinion that the multimedia and activities to enhance knowledge about arts and cultures for community youths through social lab were beneficial for both the organizers and the community youths. The organizers learned how to work as a team and they could use their skills in real situations. They realized the importance of giving, especially teaching knowledge about arts and cultures for community youths. The community youths learned to spend their free time on useful activities and did not involve in drug abuse. They also learned new skills and they could do dancing performance to earn their living on the weekends and holidays or when there were festive events. It could be concluded that the multimedia and activities to enhance knowledge about arts and cultures for community youths through social lab were of good quality and could be applied for real use.
\end{abstract}

Keywords: multimedia, activities, arts and cultures, community youths, social lab

\section{Background and Significance}

Erguc (2018) said that culture is a social heritage. It plays a significant role in societal development. The way to share culture and art, to deliver them to individuals and to carry it over into the future is through communication. In today's world, the production, interpretation, reimagining and storage of the entire world's knowledge take place through digital media. What's more, the fact that these channels are accessible at all times allows for the creation of a collective memory. 
Robinson (2013) said that creativity is an activity related to thought and imagination. The aim of such activity is to succeed in creating good values. Creativity is not limited to arts because it is the basis of scientific advancement, mathematics, technology, politics, business and every aspect of life. In education, creativity plays an important role in helping learners from all ages to develop their learning and to understand reality and problems in societies.

Through different viewpoints and experiences, learners become complete. Moreover, it helps learners to increase 8 types of intelligence according to the principle of Multiple Intelligence. Creativity is a process in the human brain for perception and intellect, resulting in the ability to relate things which impress you or to have an imagination and to inspire people to endeavor to create things through thinking processes. Theories and principles in creativity are related to skills, knowledge, intellect, resourcefulness, imagination and inspiration before a new idea of arts can be conceived. Regarding performing arts, they are not just for conservation of culture but also for creativity and refinement. This is like a tree before it can grow its roots (Ritboon, 1997).

Hassan (2014) said that social labs have been quietly brewing for almost twenty years. Hundreds of people around the world have been and are developing social labs. Thousands more have participated in them. There are labs focused on eliminating poverty, on water sustainability, on transforming media, on government, on climate, on social innovation, and on many more issues. A growing number of people are focusing their heads, hearts, and hands on addressing complex social challenges. The people running these labs represent a new breed- they're not simply scientists or academics, and neither are they activists or entrepreneurs. They're all of these things and a few things we don't have good names for yet. They're making the case for and launching social labs around the world, trying to address some of our most difficult challenges. Social labs are platforms for addressing complex social challenges that have three core characteristics.

1) They are social. Social labs start by bringing together diverse participants to work in a team that acts collectively. They are ideally drawn from different sectors of society, such as government, civil society, and the business community. The participation of diverse stakeholders beyond consultation, as opposed to teams of experts or technocrats, represents the social nature of social labs.

2) They are experimental. Social labs are not one-off experiences. They're ongoing and sustained efforts. The team doing the work takes an iterative approach to the challenges it wants to address, prototyping interventions and managing a portfolio of promising solutions. This reflects the experimental nature of social labs, as opposed to the project-based nature of many social interventions.

3) They are systemic. The ideas and initiatives developing in social labs, released as prototypes, aspire to be systemic in nature. This means trying to come up with solutions that go beyond dealing with a part of the whole or symptoms and address the root cause of why things are not working in the first place.

Social labs comply with the missions of King Mongkut's University of Technology Thonburi (KMUTT) to develop and plan the strategies to do a follow-up of the quality assurance of the university. Many activities and areas have been designed as social labs and therefore some communities have become part of learning centers for experience and knowledge so that university students, staff members and alumni can work together to share their knowledge with the local people. The key objective is to gather local wisdom and apply it to the communities through technology and knowledge base. This will increase the productivity of the communities and the communities will become community enterprise. Moreover, it helps people to be aware of natural resources and environments (Ritboon, 1997). Faculty of Industrial Education and Technology, KMUTT has been working with the community under the bridge zone 1 as part of Social Lab initiated by the university since 2012 (King Mongkut's University of Technology Thonburi, 2014).

The community under the bridge was formed out of homeless people who used to live under the bridge. Bangkok Metropolitan Administration worked with National Housing Authority to find residence for these people and now their community was in Soi Pracha-Utit 76, Toong-kru District, Bangkok. It is around 10 kilometers away from KMUTT campus. Nowadays there are 182 families. The majority of the community members (around $70 \%$ ) work as itinerant junk buyers. Most are poor and they have problems related to drugs, education and youth. In 2018, the researcher asked the Community Chair, that is Leewangsee (2018) and found that the community would like KMUTT, especially Department of Educational Communications and Technology, Faculty of Industrial Education and Technology, to develop multimedia and activities to enhance knowledge about Thai dance performances by using long single-head drums. Around 20 young people participated and they could work as performers on the weekends and holidays to earn their living. Moreover, the community wanted voluntary workers to paint the fences around the social lab because the community had got funding to renovate their building but not enough to paint the fences.

According to the above-mentioned rationale, the researcher would like to extend the research and therefore 
decided to develop multimedia and activities to enhance knowledge about arts and cultures for community youths at the community under the bridge zone 1 . The focus was on dancing performance alongside single-head drums. This research involved collaboration with graduate students from the LTM652 Principle and Theories of Mass Communication course. This course involved both lecture and lab sessions so that learners can apply their knowledge of mass communication in real practice and make it useful for the general public. This instructional approach complies with the mission of the Department which reads: Graduates from the Educational Communications and Technology Department have knowledge and skills (both theoretical and practical) and they can think analytically and synthetically in a systematic order to seek knowledge and expertise in communication. They will work in accordance with ethical values and moral conduct and they will use their knowledge in an appropriate manner to meet the demands of the society (Department of Educational Communications and Technology, King Mongkut's University of Technology Thonburi, 2018). This complies with an active learning approach and it involves community-based learning through social service.

\section{Objective}

1) To develop multimedia and activities to enhance knowledge about arts and cultures for community youths through social lab at the community under the bridge zone 1

2) To determine the quality of the multimedia and activities to enhance knowledge about arts and cultures for community youths through social lab at the community under the bridge zone 1

3) To examine the learning achievement of knowledge about arts and cultures for community youths through social lab at the community under the bridge zone 1

4) To evaluate the satisfaction of the sampling group towards the developed multimedia and activities to enhance knowledge about arts and cultures for community youths through social lab at the community under the bridge zone 1

5) To evaluate the after-action review (AAR) of the organizers on the multimedia and activities to enhance knowledge about arts and cultures for community youths through social lab at the community under the bridge zone 1

\section{Research Hypotheses}

1) The quality of the multimedia and activities to enhance knowledge about arts and cultures for community youths through social lab at the community under the bridge zone 1 would be at least at a good level.

2) The youths would show an increase in their learning achievement of knowledge about arts and cultures for community youths through social lab at the community under the bridge zone 1 and their average post-test score would be higher than their pre-test score with statistical significance at the.05 level.

3) The sampling group would express at least a high level of satisfaction towards the multimedia and activities to enhance knowledge about arts and cultures for community youths through social lab at the community under the bridge zone 1.

4) The after-action review (AAR) of the organizers on the multimedia and activities to enhance knowledge about arts and cultures for community youths through social lab at the community under the bridge zone 1 would be at least at a good level.

\section{Expected Outcomes}

1) The multimedia and activities to enhance knowledge about arts and cultures for community youths through social lab at the community under the bridge zone 1 would be of a good quality.

2) This would be used as a model to develop an active learning approach for community-based learning through social service in other courses.

3) This would be used as a model to develop projects which promote youth learning through social lab in other communities.

\section{Research Scope}

The researcher developed the multimedia and activities to enhance knowledge about arts and cultures for community youths through social lab at the community under the bridge zone 1 with the contents about dancing performance alongside single-head drums. The multimedia included vinyl media and video clips to teach dancing performance alongside music from single-head drums. The video clips were made by students who got scholarship from KMUTT for their art and cultural skills and the fence-painting activity was done by graduate students from the LTM652 Principle and Theories of Mass Communication course in the first semester of the academic year 
2018.

\section{1) Population, Sampling Group and Expert Panels}

The population, sampling group and expert panels in this research were as follows:

2) Populations

The population was the people who lived in the community under the bridge zone 1 in Soi Pracha-Utit 76. There were around 800 people. (Department of Educational Communications and Technology, King Mongkut's University of Technology Thonburi, 2018)

\section{3) Sampling Groups}

The people who had lived in the community under the bridge zone 1 for over 2 years had participated in this research from the beginning till the end. There were 120 people who filled out the questionnaires. They were chosen using purposive sampling method. Out of these people, 100 were local people whereas 20 people were community youths who participated in activities to enhance their knowledge about arts and cultures.

\section{4) Expert Panel}

Experts in this study were specialists in their area of work. They would evaluate the quality of the multimedia and activities to enhance knowledge about arts and cultures for community youths through social lab. They were chosen using specified sampling method out of those who were qualified and willing to be in the expert panels. The first panel consisted of 3 experts in contents. The second panel consisted of 3 experts in media and activities. The third panel consisted of 3 experts in evaluating the IOC value of questionnaire items. The expert panels would use the pre-defined criteria.

\section{Research Tools}

Research tools in this study were as follows:

1) The quality evaluation form for the multimedia and activities to enhance knowledge about arts and cultures for community youths through social lab at the community under the bridge zone 1 .

2) The learning achievement test on the knowledge about arts and cultures for community youths through social lab at the community under the bridge zone 1 .

3) The satisfaction survey for the sampling group towards the multimedia and activities to enhance knowledge about arts and cultures for community youths through social lab at the community under the bridge zone 1.

4) The activity to get after-action review (AAR) of the organizer on the multimedia and activities to enhance knowledge about arts and cultures for community youths through social lab at the community under the bridge zone 1.

\section{Data Analysis}

The research data were analyzed using mean score, standard deviation, and after-action review (AAR) by the organizer.

\section{Research Results}

Table 1. The outcome of the development of the multimedia and activities to enhance knowledge about arts and cultures for community youths through social lab at the community under the bridge zone 1 followed the ADDIE Model (Branch, 2009)

\begin{tabular}{|c|c|c|}
\hline Phase & Month & Details \\
\hline 1. Analysis & August & The demands of the community were analyzed and plans were made through interviews. \\
\hline 2. Design & September & $\begin{array}{l}\text { The first draft of the project proposal entitled "Multimedia and Activities to Enhance Knowledge about Arts } \\
\text { and Cultures for Community Youths through Social Lab". }\end{array}$ \\
\hline 3. Development & October & $\begin{array}{l}\text { Fieldwork with photos of the community, the development of video clips to teach dancing performance } \\
\text { alongside single-head drums to be suitable to the project. }\end{array}$ \\
\hline $\begin{array}{l}4 . \\
\text { Implementation }\end{array}$ & November & $\begin{array}{l}\text { The project was launched to enhance knowledge about arts and cultures for community youths through } \\
\text { social lab. }\end{array}$ \\
\hline 5. Evaluation & December & After-action review of the organizer to conclude the project. \\
\hline
\end{tabular}



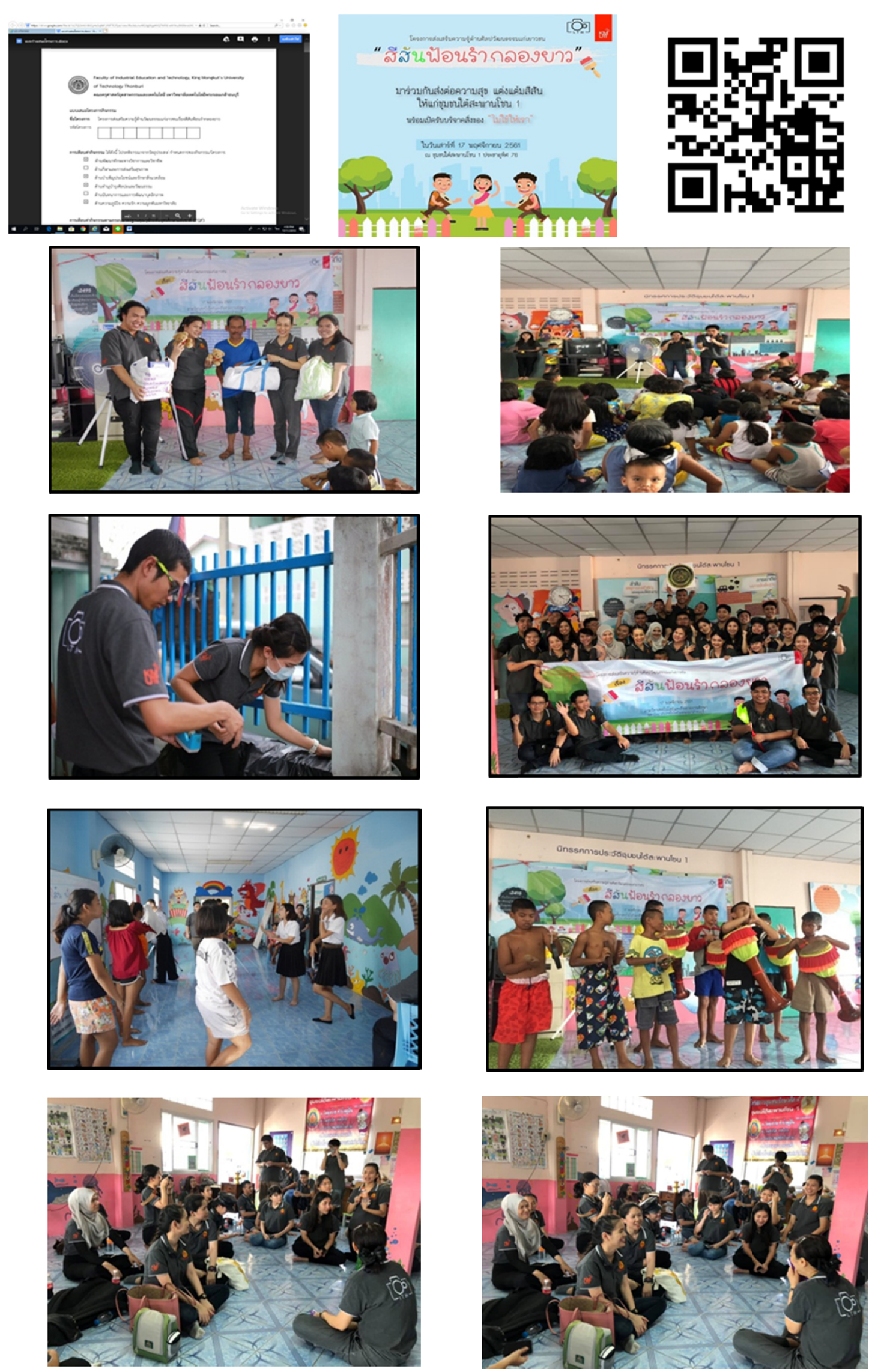

Figure 1. Multimedia and activities to enhance knowledge about arts and cultures 
Figure 1 shows multimedia and activities to enhance knowledge about arts and cultures for community youths with the focus on dancing performance alongside single-head drums at the community under the bridge zone 1 in the first semester of the academic year 2018 .

Table 2. The results from the quality evaluation of the multimedia and activities to enhance knowledge about arts and cultures for community youths through social lab at the community under the bridge zone 1 by the experts in contents and the experts in media

\begin{tabular}{lccc}
\hline \multirow{2}{*}{ Item } & \multicolumn{3}{c}{ Quality Level } \\
\cline { 2 - 5 } & Mean & S.D. & Meaning \\
\hline 1. Contents & & & \\
1.1 The contents were easy to understand. & 4.67 & 0.58 & Very good \\
1.2 The contents were clear. & 4.00 & 0.00 & Good \\
1.3 The contents were complete. & 4.33 & 0.58 & Good \\
1.4 The contents were correct and accurate. & 4.67 & 0.58 & Very good \\
1.5 The contents were suitable for the community youths. & 4.67 & 0.58 & Very good \\
Mean & 4.46 & 0.26 & Good \\
\hline 2. Media and Activities & & & \\
2.1 The colors and graphics were suitable. & 4.67 & 0.58 & Very good \\
2.2 The music and sound effects were suitable. & 4.33 & 0.58 & Good \\
2.3 The multimedia were well-designed. & 5.00 & 0.00 & Very good \\
2.4 The learning activities were suitable. & 4.33 & 0.58 & Good \\
2.5 The media and activities were suitable for the community youths. & 4.67 & 0.58 & Very good \\
Mean & 4.60 & 0.26 & Very good \\
\hline
\end{tabular}

According to the analysis of the quality evaluation of the multimedia and activities to enhance knowledge about arts and cultures for community youths through social lab at the community under the bridge zone 1 by the experts in contents and the experts in media and activities, it was found that the quality of the contents was at a good level with mean score of 4.46 and standard deviation of 0.26 . The quality of the media and activities was at a very good level with mean score of 4.60 and standard deviation of 0.26 , confirming the research hypothesis.

Table 3. The learning achievement of the community youths for the knowledge about arts and cultures through social lab at the community under the bridge zone 1

\begin{tabular}{lcccccl}
\hline Test & $\bar{X}$ & S.D. & $\bar{D}$ & S.D. & t & Sig. (1-tailed) \\
\hline Pre-test & 4.43 & 0.98 & 4.00 & 1.00 & $10.58^{*}$ & 0.0000 \\
Post-test & 8.43 & 0.53 & & & & \\
\hline
\end{tabular}

According to the results for the learning achievement of knowledge about arts and cultures for community youths through social lab at the community under the bridge zone 1, the average pre-test and post-test scores were 4.43 and 8.43, respectively. When the pre-test and post-test scores were compared, it was found that the average post-test score was higher with statistical significance at the.05 level, confirming the research hypothesis.

Table 4. The results from the satisfaction survey of the sampling group towards the multimedia and activities to enhance knowledge about arts and cultures for community youths through social lab at the community under the bridge zone 1

\begin{tabular}{|c|c|c|c|c|}
\hline \multirow{2}{*}{ No } & \multirow{2}{*}{ Item } & \multicolumn{3}{|c|}{ Satisfaction level } \\
\hline & & Mean & S.D. & Meaning \\
\hline 1. & The media contents and activities were clear. & 4.41 & 1.07 & High \\
\hline 2. & The media contents and activities were suitable for community youths. & 4.56 & 0.53 & The highest \\
\hline 3. & The media were well-designed. & 4.59 & 0.57 & The highest \\
\hline 4. & The music and sound effects were suitable. & 4.59 & 0.54 & The highest \\
\hline 5. & The designed learning activities were suitable. & 4.68 & 0.52 & The highest \\
\hline
\end{tabular}




\begin{tabular}{|c|c|c|c|c|}
\hline 6. & $\begin{array}{l}\text { The contents on dancing performance alongside single-head drums met the } \\
\text { demands of the community. }\end{array}$ & 4.67 & 0.51 & The highest \\
\hline 7. & The social lab was suitable. & 4.65 & 0.51 & The highest \\
\hline 8. & $\begin{array}{l}\text { The presenter's demonstration was suitable for teaching knowledge about arts } \\
\text { and cultures. }\end{array}$ & 4.72 & 0.52 & The highest \\
\hline 9. & $\begin{array}{l}\text { The activities could enhance knowledge about arts and cultures for community } \\
\text { youths. }\end{array}$ & 4.67 & 0.49 & The highest \\
\hline 10. & $\begin{array}{l}\text { The activities could create a good relationship between the community and the } \\
\text { university. }\end{array}$ & 4.71 & 0.49 & The highest \\
\hline Mean & & 4.63 & 0.56 & The highest \\
\hline
\end{tabular}

According to the results of the satisfaction survey of the sampling group towards the multimedia and activities to enhance knowledge about arts and cultures for community youths through social lab at the community under the bridge zone 1, the satisfaction was at the highest level with mean score of 4.63 and standard deviation of 0.56 , confirming the research hypothesis.

The results from the after-action review (AAR) of the organizer on the knowledge about arts and cultures for community youths through social lab at the community under the bridge zone 1 showed that it was at a good level, confirming the research hypothesis. The organizers expressed their opinion that the project followed the active Learning approach with community-Based Learning through Social Service. It was beneficial for both the organizers and the community youths. The organizers learned how to work as a team and they learned to be proud of their skills and their circle of friends also expanded. They could use their skills in real situations and they realized the importance of giving, especially teaching knowledge about arts and cultures for community youths. The community youths learned to spend their free time on useful activities and did not involve in drug abuse. They also learned new skills and they could do dancing performance to earn their living on the weekends and holidays or when there were festive events. When they performed in the neighborhood, they received tips or pocket money because they did not set the professional price. These are the outcomes of the continual project which has been done in 2017 and 2018.

\section{Discussions}

The research findings show that the multimedia and activities about dancing performance alongside single-head drums which were developed by the researchers for community youths at the community under the bridge zone 1 could be considered as a social lab. The New HoRRizon Project (2018) says that social labs must involve team working, procedures and many objectives such as the development of technology for the future, the development of leadership, the development of industrial technology, the development of environment, the development of transportation and others. These social issues need to be analyzed, observed and developed as social labs and the researchers have been engaging in social labs with the community under the bridge zone 1 for over 5 years with research output in international journals. To cite a few, in 2014, we did research about activity based learning kits for children in a disadvantaged community according to the project entitled "Vocational Teachers Teach Children to Create Virtuous Robots from Garbage" (Thamwipat, Princhankol, Khumphai, \& Sudsangket, 2014). In 2015, we ran a project into the development of student documentary short film on disadvantaged people in the community under the bridge zone 1 in Bangkok entitled "UTOPIA" (Thamwipat and Boonrom, 2015) and there was another project about the development of media and activities to promote learning for children in disadvantaged communities and this was a case study of creative media at community under the bridge zone 1 regarding sex education (Princhankol \& Thamwipat, 2015). In 2017 we developed a lesson based on the 'Service-Learning' principle through the project to create a community calendar to promote 12 values (Thamwipat, Princhankol, \& Kaewket, 2017). In 2018, the research papers included the development of media activities by undergraduate students in order to promote agricultural tourism community enterprise according to the principles of social service learning and community-based leaning (Thamwipat, Princhankol, \& Meejaleurn, 2018) and the development of media and special event to support knowledge of arts and culture entitled "Dancing with Single-Head Drum Accompaniment" for young people through social service learning and community-based learning (Thamwipat \& Princhankol, 2018). These research works show that the community under the bridge zone 1 is a social lab which has undergone different procedures and the location has been specifically known for the work with clear objectives to develop learning in different areas.

This year, the researcher organized the activity to develop multimedia including vinyl media and video clips to teach dancing performance alongside single-head drums. The demonstration was run by students who got 
scholarship from KMUTT for their art and cultural skills. The fence-painting activity was done by graduate students from the LTM 652 Principle and Theories of Mass Communication course. The organizers analyzed, designed and developed multimedia and activities in accordance with the ADDIE Model and this practice is supported by Branch (2009) who says that the ADDIE process is used to introduce an approach to instruction design that has a proven record of success. Therefore, the researcher chose this approach as part of research and development for the multimedia and activities in the first semester of the academic year 2018.

The research findings show that the quality of the contents was at a good level $(\overline{\mathrm{x}}=4.46, \mathrm{~S} . \mathrm{D}=0.26)$. The quality of the media and activities was at a very good level $(\overline{\mathrm{x}}=4.60, \mathrm{~S} . \mathrm{D}=0.26)$. The findings confirm the research done by Thamwipat, Kojirapan, and Diangsanoi (2017) who conducted a research study into the design of infographic media about TV variety show production by Amarin TV company and the research results showed that the quality of the contents as evaluated by the experts were at a good level $(\overline{\mathrm{x}}=4.50, \mathrm{~S} . \mathrm{D}=0.57)$ whereas the quality of the media presentation as evaluated by the experts was at a very good level $(\overline{\mathrm{x}}=4.75$, S.D $=0.32)$.

The learning achievement of the students from their pre-test and post-test scores showed that their average post-test score was higher with statistical significance at the.05 level. This finding confirms the research hypothesis and it complies with the research by Pansatan and Princhankol (2015) who conducted research into the development of learning center for children in the community under the bridge zone 1 to develop their learning in science classes through a virtuous garbage robot.

The satisfaction of the sampling group was at the highest level $(\overline{\mathrm{x}}=4.63$, S.D $=0.56)$. It confirms the research hypothesis and complies with the research by Homchan (2015) who conducted a research study into the development of activities to encourage reading habits among primary school students. It was found in her research that the reading activities which included narrations, crossword puzzles, interesting news, storytelling, and small book projects helped learners to gain more knowledge, enjoy their reading, increase their creativity and be able to use knowledge in real life. The satisfaction level was at the highest level. The finding was also similar to the research by Chuechuean and Wanitwattanawornchai (2015) who conducted a study into the development of activities for learners entitled "Creative Dancing Performance for Thai-Burmese Relations among Primary Students" and it was found that the activities which incorporated experiences and practices were suitable for learners in the classroom and the teacher played an important role in helping learners to gain skills and practice in the activities. The local experts also talked about dancing performances in Myanmar and there were many activities for learners to engage with, for example, video clips, brainstorming, hands-on practice, and creativity to make a good relationship between Thailand and Myanmar through dancing performances. Therefore, sampling group showed the highest level of satisfaction.

The after-action review showed that it was at a good level. It confirms the research hypothesis and the organizers believe that activities which promote knowledge and culture among youth members in the community are useful for the learners. Moreover, these social labs are useful for the organizers as well because they learn how to work as a team and they can apply their skills in real use. They realize that it is important to be givers, especially givers of knowledge and culture to the community so that the children use their time in good activities and do not involve in drug. Moreover, they can use their ability to earn their living when there are events and activities. This finding is similar to the one in the research study by Wiangkam and Phiromjitphong (2017) who studied the development of experiential learning activities to enhance the public mind of high school students and found that the students expressed the highest level of satisfaction towards the experience-based activities to create a sense of public service $(\overline{\mathrm{x}}=4.68, \mathrm{~S} . \mathrm{D}=0.25)$ because such activities are suitable in terms of contents and evaluation. Those activities are extracurricular and they do not focus on one particular subject but they allow learners to practice in real life. Students have learned to share their ideas with others and they have had more chances to go outside their school to gain new experiences, resulting in a change in their knowledge and behaviour.

The research findings in this study arise from the Active Learning approach (Stanford Teaching Commons, 2018) in which learners engaged in social service learning through a social lab in a community, in the same way as Stanford Teaching Commons say: "Active learning" means students engage with the material, participate in the class, and collaborate with each other. Don't expect your students simply to listen and memorize; instead, have them help demonstrate a process, analyze an argument, or apply a concept to a real-world situation. When you invite students to actively participate in the learning environment, they take more responsibility for their performance in the course. Similarly, when they have an opportunity to make decisions about what they learn and how they use that knowledge, students see a course as more valuable and more directly related to their goals. It helps students be the main actors in the use of media within the community which reflects the principle of development communication (Thusong Service Center, 2000). Development communication describes an approach to communication which provides communities with information they can use in bettering their lives, 
which aims at making public programmes and policies real, meaningful and sustainable. Such information must be applied in some way as part of community development but it must also address information needs which communities themselves identified. The outcome of this approach, in short, is to make a difference in the quality of life of communities.

\section{Suggestions}

\subsection{Suggestions from This Research}

1) Educational institutes should promote instructors to use the active learning approach from the policy level to the staff level and there should be research grants to support such works to contribute to the institutes, students and people in the community.

2) Activities in social labs should be organized with procedures and principles to support the activities. After the activities have been accomplished, there should be a presentation of such activities to the general public so that the activities become visible. This way, the social labs in the community will be stronger and more recognized in both academic and professional contexts.

\subsection{Suggestions for Further Research}

1) There should be a study into factors which contribute to the use of Active Learning through Social Labs.

2) There should be a qualitative study to follow-up the learning achievement and skills of the youth in the community.

\section{Acknowledgements}

The researcher would like to extend gratitude towards the Faculty of Industrial Education and Technology, King Mongkut's University of Technology Thonburi and other private sectors for their support in this research.

\section{References}

Branch, R. M. (2009). Instructional Design: The ADDIE approach (Vol. 722). Springer Science \& Business Media.

Chuechuean, T., \& Wattanawornchai, S. (2015). The Development of Activities for Learners: Creative Dancing Performance for Thai-Burmese Relations among Primary Students. Journal of Humanities, Social Sciences and Arts, January-April 2015.

Department of Educational Communications and Technology, King Mongkut's University of Technology Thonburi. (2018). History, Vision, and Mission. Retrieved from http://ect.kmutt.ac.th/ectweb/

Erguc, D. A. (2018). Communicating culture and art. Retrieved from https://www.eacd-online.eu/insights/blog/communicating-culture-and-art

Hassan, Z. (2014). The Social Labs Revolutions A New Approach to Solving Our Most Complex Challenges. Barrett-Koehler Publishers.

Homchan, N. (2015). Research and Development of Activities to Encourage Reading Habits among Primary School Students. The 17th Academic Conference for Graduate Students and the 5th Seminar for Research Distribution to the Community.

King Mongkut's University of Technology Thonburi. (2014). University and community and Social Lab. Retrieved from http://www2.kmutt.ac.th/thai/abt_history/info_report/KMUTT-Social-Report-2556-2557.pdf

Leewangsee, C. (2018). Community Chair of the Community under the Bridge Zone 1. Interview [November 1st, 2018].

Pansatan, W., \& Princhankol, P. (2015). The Development of Learning Center for Children in the Community under the Bridge Zone 1 to Develop their Learning in Science Classes through a Virtuous Garbage Robot. The 29th National Conference on Educational Technology NCET2015, 22-23 January 2015.

Robinson, K. (2013). Schools Kill Creativity. Retrieved from https://www.ted.com/talks/ken_robinson_says_schools_kill_creativity?language=th

Stanford Teaching Commons. (2018). Promoting Active Learning. Retrieved from https://teachingcommons.stanford.edu/resources/learning-resources/promoting-active-learning

Thamwipat, K., \& Boonrom, K. (2015). Development of the Student Documentary Short Film on Disadvantaged People in the Community under the Bridge Zone 1 in Bangkok Entitled UTOPIA. International Teacher Education Conference (ITEC 2015), September 2-4, 2015, Saint Petersburg, Russia. 
Thamwipat, K., \& Princhankol, P. (2018). The Development of Media and Special Event to Support Knowledge of Arts and Culture Entitled "Dancing with Single-Head Drum Accompaniment" for Young People through Social Service Learning and Community-Based Learning. International Education Studies, 11(12), 133-139. https://doi.org/10.5539/ies.v11n12p133

Thamwipat, K., Kojirapan, P., \& Diangsanoi, K. (2017). The Design of Infographic Media about TV Variety Show Production by Amarin TV Company. Journal of Nitessiam Parithat, 16(20).

Thamwipat, K., Pornpapatsorn, P., \& Kaewket, K. (2017). Developing a Lesson Based on the 'Service-Learning' Principle through the Project to Create a Community Calendar to Promote 12 Values. 3rd International Conference on Education and Distance Learning 2017. Galle Face Hotel, Colombo, Srilanka, 28th April 2017.

Thamwipat, K., Pornpapatsorn, P., Yampinij, S., \& Meejaleurn, S. (2018). The Development of Media Activities by Undergraduate Students in Order to Promote Agricultural Tourism Community Enterprise According to the Principles of Social Service Learning and Community-Based Leaning. International Education Studies, 11(5), 38-45. https://doi.org/10.5539/ies.v11n5p38

Thamwipat, K., Princhankol, P., Khumphai, T., \& Sudsangket, V. (2014). Activity Based Learning Kits for Children in a Disadvantaged Community According to the Project Vocational Teachers Teach Children to Create Virtuous Robots from Garbage. International Journal of Advanced Computer and Applications, 5(8), 168-172. https://doi.org/10.14569/ijacsa.2014.050825

The New Horizon Project. (2018). What is Social Lab. Retrieved from http://newwhorizon.eu/social-labs/

Thusong Service Center. (2000). Development Communication - An Approach to A DemocraticPpublic Information. Retrieved from http://www.thusong.gov.za/documents/artic_pres/devcomm.htm

Wiangkam, B., \& Phiromjitphong, S. (2017). Development of Experiential Learning Activities to Enhance the Public Mind of High School Students. Retrieved from http://www.human.ubru.ac.th/journal/wpcontent/ uploads/2018/04/1-Boonma.pdf

\section{Copyrights}

Copyright for this article is retained by the author(s), with first publication rights granted to the journal.

This is an open-access article distributed under the terms and conditions of the Creative Commons Attribution license (http://creativecommons.org/licenses/by/4.0/). 